\title{
Cetacean rapid assessment: an approach to fill knowledge gaps and target conservation across large data deficient areas
}

Gill T. Braulik, Magreth Kasuga, Anja Wittich, Jeremy J. Kiszka, Jamie MacAulay, Doug Gillespie, Jonathan Gordon, Said Shaib Said, and Philip S. Hammond

\begin{tabular}{|c|c|}
\hline Date of deposit & 9 August 2017 \\
\hline Document version & Author's accepted manuscript \\
\hline Access rights & $\begin{array}{l}\text { Copyright ( } 2017 \text { John Wiley \& Sons, Ltd. This work has been } \\
\text { made available online in accordance with the publisher's policies. } \\
\text { This is the author created, accepted version manuscript following } \\
\text { peer review and may differ slightly from the final published } \\
\text { version. }\end{array}$ \\
\hline $\begin{array}{l}\text { Citation for } \\
\text { published version }\end{array}$ & $\begin{array}{l}\text { Braulik, G. T., Kasuga, M., Wittich, A., Kiszka, J. J., MacAulay, J., } \\
\text { Gillespie, D., Gordon, J., Said, S. S., \& Hammond, P. S. (2018). } \\
\text { Cetacean rapid assessment: an approach to fill knowledge gaps } \\
\text { and target conservation across large data deficient areas. Aquatic } \\
\text { Conservation: Marine and Freshwater Ecosystems, 28(1), 216- } \\
230 .\end{array}$ \\
\hline $\begin{array}{l}\text { Link to published } \\
\text { version }\end{array}$ & https://doi.org/10.1002/aqc.2833 \\
\hline
\end{tabular}

Full metadata for this item is available in St Andrews Research Repository at: https://research-repository.st-andrews.ac.uk/ 


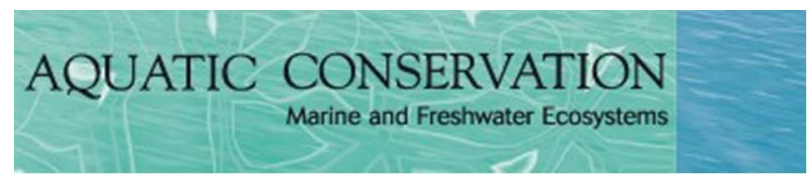

\section{Cetacean rapid assessment: an approach to fill knowledge gaps and target conservation across large data deficient areas}

\begin{tabular}{|c|c|}
\hline Journal: & Aquatic Conservation: Marine and Freshwater Ecosystems \\
\hline Manuscript ID & AQC-17-0004.R1 \\
\hline Wiley - Manuscript type: & Research Article \\
\hline Date Submitted by the Author: & 19-Jun-2017 \\
\hline Complete List of Authors: & $\begin{array}{l}\text { Braulik, Gill; Wildlife Conservation Society, Tanzania Program; University of } \\
\text { St. Andrews, Scottish Oceans Institute } \\
\text { Kasuga, Magreth; Wildlife Conservation Society, Tanzania Program } \\
\text { Wittich, Anja; 23 Adamson Terrace } \\
\text { Kiszka, Jeremy; Florida International University, Department of Biological } \\
\text { Sciences } \\
\text { Macaulay, Jamie; University of St. Andrews, Scottish Oceans Institute } \\
\text { Gillespie, Doug; University of St. Andrews, Scottish Oceans Institute } \\
\text { Gordon, Jonathan; University of St. Andrews, Scottish Oceans Institute } \\
\text { Said, Said; University of Dar es Salaam, Institute for Marine Science } \\
\text { Hammond, Philip; University of St. Andrews, Scottish Oceans Institute }\end{array}$ \\
\hline $\begin{array}{l}\text { Broad habitat type } \\
\text { (mandatory) select 1-2: }\end{array}$ & ocean $<$ Broad habitat type, coastal $<$ Broad habitat type \\
\hline $\begin{array}{l}\text { General theme or application } \\
\text { (mandatory) select 1-2: }\end{array}$ & $\begin{array}{l}\text { survey }<\text { General theme or application, biodiversity }<\text { General theme or } \\
\text { application }\end{array}$ \\
\hline $\begin{array}{l}\text { Broad taxonomic group or } \\
\text { category (mandatory, if } \\
\text { relevant to paper) select } 1-2 \text { : }\end{array}$ & mammals < Broad taxonomic group or category \\
\hline $\begin{array}{r}\text { Impact category (mandatory, } \\
\text { if relevant to paper) select } 1- \\
2:\end{array}$ & fishing < Impact category, shipping $<$ Impact category \\
\hline
\end{tabular}


4 Gill T. Braulik ${ }^{1,2}$, Magreth Kasuga ${ }^{1}$, Anja Wittich ${ }^{3}$, Jeremy J. Kiszka ${ }^{4}$, Jamie MacCaulay ${ }^{2}$,

5 Doug Gillespie $^{2}$, Jonathan Gordon ${ }^{2}$, Said Shaib Said ${ }^{5}$, Philip S. Hammond ${ }^{2}$

$6 \quad{ }^{1}$ Wildlife Conservation Society Tanzania Program, Zanzibar, Tanzania

$7 \quad 2$ Sea Mammal Research Unit, Scottish Oceans Institute, University of St Andrews, St

8 Andrews, Fife KY16 8LB, United Kingdom

$9 \quad 323$ Adamson Terrace, Leven, Fife, United Kingdom

$10{ }^{4}$ Department of Biological Sciences, Florida International University, North Miami, USA

$11{ }^{5}$ Institute of Marine Science, University of Dar es Salaam, Tanzania

12 Email: gillbraulik@downstream.vg 
14 Abstract

15 1. Many species and populations of marine megafauna are undergoing substantial 16 declines, whilst many are also very poorly understood. Even basic information on 17 species presence is unknown for tens of thousands of kilometres of coastline, 18 particularly in the developing world, which is a major hurdle to their management 19 and conservation.

202 . Rapid ecological assessment is a valuable tool used to identify and prioritize areas for conservation, however, this approach has never been clearly applied to marine cetaceans. Here a rapid assessment protocol is outlined that will generate broadscale, quantitative, baseline data on cetacean communities and potential threats, that can be conducted rapidly and cost-effectively across whole countries, or regions.

3. The rapid assessment was conducted in Tanzania, East Africa, and integrated collection of data on cetaceans from visual, acoustic, and interview surveys with existing information from multiple sources to provide low resolution data on cetacean community relative abundance, diversity, and threats. Four principal threats were evaluated and compared spatially using a qualitative scale: cetacean mortality in fishing gear (particularly gillnets); cetacean hunting, consumption or use by humans; shipping related collision risk and noise disturbance; and dynamite fishing.

4. A total of 91 groups of 11 species of marine mammal were detected during field surveys. Potentially the most important area for cetaceans was the Pemba Channel, a deep, high-current waterway between Pemba Island and mainland Africa, where 
by far the highest relative cetacean diversity and high relative abundance were

37

38

39

40

41

42

43 Keywords: cetaceans; distribution; environmental impact assessment; management, marine

$44 \quad$ spatial planning; rapid assessment; Tanzania.

45 


\section{Introduction}

47 Marine megafauna, such as elasmobranchs, marine mammals and sea turtles are some of

48 the most iconic components of ocean biodiversity, yet many populations are undergoing

49 large and unprecedented declines due to unsustainable direct exploitation or incidental

50 mortality in fisheries (Heithaus, Frid, Wirsing, \& Worm, 2008; Lewison, Crowder, Read,

$51 \&$ Freeman, 2004). Beyond their flagship status, these species can be critical to maintain

52 the structure and function of marine ecosystems and their loss can have large negative

53 ecological consequences (Bowen, 1997; Ferretti, Worm, Britten, Heithaus, \& Lotze, 2010).

54 Conservation of cetaceans globally is seriously challenged because even basic information

55 on species presence is lacking for tens of thousands of kilometres of coastline in many

56 places, especially in the developing world (Kaschner, Quick, Jewell, Williams, \& Harris,

57 2012). Recent modelling studies suggest that hotspots of cetacean diversity as well as

58 many at-risk species are likely to occur in some of these data deficient areas (Davidson et

59 al., 2011; Kaschner, Tittensor, Ready, Gerrodette, \& Worm, 2011; Pompa, Ehrlich, \&

60 Ceballos, 2011).

61

62 In contrast to many other species groups, cetaceans are time consuming and expensive to

63 survey and assess. This is because they generally occur at low densities, spend most of their

64 time underwater, and range over wide areas far from land. Consequently, their study

65 involves chartering expensive sea-worthy vessels or light aircraft, and surveys often need to

66 last for many weeks or be repeated over multiple years to generate sufficient data for robust

67 population assessments (Jewell et al., 2012). The result of a lack of basic information, 
68 combined with the perceived difficulty and expense of collecting dedicated data to fill these

69

70

71

72

73

74

75

76

77

78

79

80

81

82

83

84

85

86

87

88

89

90 data gaps, mean that cetaceans are often simply omitted, or are given only cursory attention in environmental impact assessments, national marine conservation planning and coastal zone management activities, or during identification of global or regional sensitive, priority or marine protected areas. Realistically the funds and expertise are not available to enable dedicated intensive studies to estimate abundance of cetaceans across the large, unevaluated coastlines of the world. What would be invaluable is a quick and relatively cost-effective way of generating robust baseline data on cetacean communities and threats from regions and numerous countries in order to identify and prioritize species and locations where there is the greatest need for, and greatest potential benefit from, conservation action.

In other environments, this is routinely accomplished using rapid ecological assessments (Alonso, Deichmann, McKenna, Naskrecki, \& Richards, 2011; Barbour, Gerritsen, Snyder, \& Stribling, 1999; Fennessy, Jacobs, \& Kentula, 2007; Maragos \& Cook, 1995; Maragos et al., 2004). A protocol for rapid assessment of cetaceans has never been clearly described or applied, but it would be an important tool in the effort to conserve cetaceans globally. Here a framework for cetacean rapid assessment is outlined, that can be applied over a period of less than one year across large data deficient areas to provide a quantitative snapshot of cetacean species diversity, relative abundance, distribution and potential threats. The objective is to fill extensive data gaps on cetacean distribution, and for the information generated to provide basic information to government agencies for conservation planning, prioritization and management. 
91 To demonstrate the approach, a rapid assessment was conducted focused on the entire coast

92 of Tanzania, a little-known but potentially important area for cetaceans, with a range of

93 habitats and threats especially relating to fishing, shipping and exploration for oil and gas.

94 Prior to this study, 16 cetacean species had been recorded in Tanzanian waters, the majority

95 odontocetes that are expected to be largely resident, but also humpback whales (Megaptera

96 novaeangliae) which are present in Tanzanian waters only from June to November (Amir,

97 Berggren, \& Jiddawi, 2012; Berggren, 2009). Previous cetacean research has concentrated

98 in south-western Unguja Island on resident coastal dolphins (Christiansen, Lusseau,

99 Stensland, \& Berggren, 2010; Stensland \& Berggren, 2007; Temple, Tregenza, Amir,

100 Jiddawi, \& Berggren, 2016), but there is very little information available on cetaceans from

101 the $800 \mathrm{~km}$ long coast of the Tanzanian mainland and several other outlying islands.

102

103 2. Methods

104 2.1. Study Area

105 The Tanzanian coastline is dominated by the warm, nutrient-poor East African Coastal

106 Current and is subject to two seasonal monsoons, the NE from December to February and

107 the SE from June to September, these interspersed with calm, rainy periods. The study area

108 encompassed the entire coastal waters of Tanzania $\left(4-10^{\circ} \mathrm{S}\right)$ out to approximately $50 \mathrm{~km}$

109 from the mainland coast, irrespective of depth (Figure 1). It included the Rufiji delta which

110 is one of the largest estuaries in eastern Africa, oceanic waters more than $1000 \mathrm{~m}$ deep in

111 the Pemba Channel and south of Kilwa, and the islands of Pemba, Unguja, Mafia and

112 Latham which have considerable fringing reefs and seagrass habitat (Figure 1). Due to 
113 time and logistical constraints, the east coasts of Pemba and Zanzibar were not included in

114 the study area.

115

116 2.2. Approach

117 One of the biggest challenges to a rapid cetacean assessment is balancing the need to keep

118 investment of time and resources low, with the use of robust, repeatable methods that

119 generate sufficient data to draw meaningful conclusions. The approach, detailed in Table 1,

120 integrates collection of data on cetaceans from visual and acoustic surveys with existing

121 information from multiple sources to provide low resolution, broad-scale data on cetacean

122 relative abundance and diversity. To evaluate threats, a largely qualitative assessment of

123 potential human impact on cetaceans (not absolute risk) was adopted, based on, and

124 adapted from, the ecological risk assessment framework described by Hobday et al. (2011),

125 which allows for a spatial comparison and prioritization of potential threats to cetaceans,

126 across the entire country.

127

128 To aid in spatial interpretation and comparison of the results in a way that is useful for

129 management, the study area was split into five 'Zones', each defined as "an area with a

130 definable boundary within which the character of habitats, biological communities, and/or

131 management issues have more in common with each other than they do with those in

132 adjacent areas" (Alliance for Zero Extinction, 2003). The zones, which align

133 approximately with the Tanzanian coastal provinces, are from north to south: Zone 1 -

134 Pemba Channel; Zone 2 - Zanzibar Channel; Zone 3 - Dar es Salaam; Zone 4 - Rufiji 
135 Delta; and Zone 5 - Mtwara/Lindi (Figure 1). The entire study area was $37,100 \mathrm{~km}^{2}$ in

136 size, with each zone as follows: $1-7425 \mathrm{~km}^{2} ; 2-5749 \mathrm{~km}^{2} ; 3-5201 \mathrm{~km}^{2} ; 4-9722 \mathrm{~km}^{2} ; 5$

$137-9003 \mathrm{~km}^{2}$.

138

139 2.3. Description of Cetacean habitat

140 The distribution of cetaceans over large-scales is influenced by environmental

141 characteristics driving the distribution of their prey: primarily depth, and also slope of the

142 sea bed, sea surface temperature, and chlorophyll-a concentration, although many other

143 factors might also influence fine scale distribution (Cañadas, Sagarminaga, \& García-

144 Tiscar, 2002; Mannocci et al., 2014; Redfern et al., 2006). Chlorophyll-a and sea surface

145 temperature (SST) can be highly variable in space and time, whilst depth and slope are

146 fixed habitat characteristics that do not change from one survey to another. We describe

147 the available habitat along the coast of Tanzania in terms of depth and slope. Using

148 General Bathymetric Chart of the Oceans (GEBCO) 2014 Grid data at 30 arc-second

149 intervals (equivalent in Tanzania to approximately 920m square pixels) and software QGIS

150 (QGIS Development Team, 2016), the amount $\left(\mathrm{m}^{2}\right)$ and proportion of habitat was

151 quantified, and presented in the following four depth classes: Very shallow: 0-20;

152 Shallow:21-100m; Moderate: 101-800m; and Deep: 801m+, and three slope classes: Flat:

$1530-2 \%$; Gentle Slope: 2.1-4\%; Steep: 4.1-7\% which correspond broadly to habitat

154 preferences of cetaceans known to occur in Tanzania.

155

156 2.4. Rapid Assessment of Cetacean Communities 
157

158

159

160

161

162

163

164

165

166

167

168

169

170

171

172

173

174

175

176

177

178

\subsubsection{Vessel-Based Cetacean Survey}

A 50-foot catamaran was used as the survey platform. Although aerial surveys quickly

cover large areas they may have a higher species misidentification rate than boat surveys; in

Tanzania vessels are more easily available, are cheaper and safer to operate, allow for

collection of more types of data (e.g. photos, biopsies, behaviour, acoustics, etc.) and also

provide more opportunities for training. The survey was designed to maximize cetacean

detections, by 1) surveying in the calmest month of the year, 2) observing from a high

viewing platform so that the field of view was large, 3) combining a visual survey with a

concurrent acoustic survey, and 4) including experienced observers in the team, as well as

inexperienced researchers undergoing training.

The visual survey was conducted using standard line transect survey methods in closing mode enabling the data to be used for abundance estimation in the future if additional data become available (Buckland et al., 2001). Line transects that ran perpendicular to the depth contours were laid out using the programme DISTANCE (Thomas et al., 2010) resulting in 36 transect lines, spaced $21 \mathrm{~km}$ apart, and a combined total of $2500 \mathrm{~km}$ of on effort survey track (Figure 1). Three observers scanned continuously for cetaceans from a platform $4 \mathrm{~m}$ above the sea surface, using 7 x 50 Fujinon marine binoculars with an internal compass. A central observer scanned 45 degrees either side of the trackline, and two observers scanned from the beam to the track. Observers took 1 hour of rest for every 1.5 hrs of observations to maintain concentration. Survey effort and sea conditions measured by the Beaufort scale were logged at 30 minute intervals throughout the day, and when conditions changed.

Surveying was suspended when sea conditions rose above Beaufort 4 . The vessel waited at 
179 port for conditions to improve and attempted to cover every transect in good weather

180 conditions. When cetaceans were first sighted, the vessel's location was recorded using a

181 GPS, the distance to the group was determined by measuring the angle subtended between

182 the sighting and the horizon using the binocular's reticules, and the angle to the group

183 determined using the internal binocular compass. Cetaceans were approached and

184 photographed, the species identified, and group size recorded with a best, high and low

185 estimate of numbers.

186

187 Coincident to the visual survey, during daylight hours, passive acoustic monitoring (PAM)

188 using a towed hydrophone array was conducted to detect the echolocation clicks, whistles,

189 and other vocalizations of cetaceans. This was especially useful to detect elusive species

190 such as beaked whales (Ziphiidae) and other odontocetes that dive to great depths and have

191 a very short surface interval meaning they were likely to be missed by the visual survey. A

192 Vanishing Point (http://vpmarine.co.uk/) stereo towed hydrophone array was deployed on

$193100 \mathrm{~m}$ of Kevlar strengthened cable. This had a towing depth of 5-10 m depending on

194 vessel speed which varied from $10-12 \mathrm{~km} / \mathrm{hr}$. The array included a high frequency

195 hydrophone pair that consisted of two Magrec HPO3 hydrophone elements spaced $0.3 \mathrm{~m}$

196 apart, each comprising a spherical hydrophone ceramic element coupled with a Magrec

197 HP02 preamplifier with $28 \mathrm{~dB}$ of gain and with a low-cut filter set to provide $-3 \mathrm{~dB}$ at 2

$198 \mathrm{kHz}$. The streamer section contained a pressure sensor to provide information on tow depth

199 and was filled with inert oil (Isopar M). A TASCAM DR680 recorder was used to make

200 continuous 2 channel, 192kHz, 24 bit recordings. A custom SoundTrap 202 High 
201 Frequency self-contained archival acoustic recorder with low flow noise housing

202 (http://www.oceaninstruments.co.nz/) was towed simultaneously from the end of the array.

203 The device had a frequency range of $20 \mathrm{~Hz}$ to $238 \mathrm{kHz}$ and sampled at $576 \mathrm{kHz}$ so that the

204 data could be used to detect the high frequency clicks produced by Kogia spp. which would

205 be missed by the lower sample rate on the array. PAMGuard was the software used to

206 analyse the PAM data (Gillespie et al., 2008).

207 A multi-stage process was used to detect the echolocation clicks of sperm whales (Physeter

208 macrocephalus), beaked whales, and Kogia spp. The PAMGuard click detector was used

209 to extract all transient sounds within frequency bands matching the typical frequency range

210 for each species' echolocation clicks. Sperm whale clicks are broad band in nature, with

211 most energy concentrated between 2 and $22 \mathrm{kHz}$ (Mellinger, Thode, \& Martinez, 2002),

212 beaked whales have species-specific frequency modulated (FM) upswept echolocation

213 clicks with a peak frequency of between 16-70 kHz (Baumann-Pickering et al., 2013;

214 Johnson, Madsen, Zimmer, Aguilar de Soto, \& Tyack, 2004) and Kogia spp. produce high

215 frequency narrow band clicks at frequencies between 100 and 150kHz (Madsen, Carder,

216 Bedholm, \& Ridgway, 2005). Detected transients in each frequency band were then

217 classified as likely belonging to the target species using a combination of automated

218 algorithms and manual inspection, based primarily on click length, frequency modulation,

219 frequency range, and (where possible) directionality of a detected click train. Multiple

220 consistent transient sounds from a similar direction are more likely to be biological in

221 origin than random noise and this provides useful additional information during the

222 classification process. Computer machine learning algorithms are being developed to 
223 automatically identify and classify cetacean whistles to species (Gillespie, Caillat, Gordon,

224 \& White, 2013; Roch et al., 2011). Development of classification algorithms using the

225 whistles of delphinids from the western Indian Ocean is still in its infancy (Erbs, Elwen, \&

226 Gridley, 2017; Gruden et al., 2016), therefore the process of developing a new classifier

227 was initiated. Whistles were detected using the PAMGuard Whistle and Moan detector

228 (Gillespie, et. al, 2013). Acoustic whistle detections that coincided with a visual sighting

229 with a positive species identification were then used to train the PAMGuard whistle

230 classifier so that it could be subsequently applied to acoustic detections that were not

231 accompanied by a visual sighting. Six species were included in the classifier: short-finned

232 pilot whale (Globicephala macrorhynchus), Fraser's dolphin (Lagenodelphis hosei), false

233 killer whale (Pseudorca crassidens), pantropical spotted dolphin (Stenella attenuata),

234 spinner dolphin (Stenella longirostris) and common bottlenose dolphin (Tursiops

235 truncatus). Indo-pacific bottlenose dolphin (Tursiops aduncus), Risso's dolphin (Grampus

236 griseus) and Indian Ocean humpback dolphin (Sousa plumbea) could not be included, even

237 though they were encountered many times, because they had low whistle rates in recordings

238 and there were insufficient data to train the classifier.

239 Cetacean encounter rate (cetacean group detections / $100 \mathrm{~km}$ of survey effort in sea

240 conditions of Beaufort 4 or less, termed 'good' conditions), individual encounter rate

241 (cetacean individuals detected/ 100km of good survey effort), and relative species richness

242 (cetacean species / $100 \mathrm{~km}$ of survey effort in good survey conditions) were determined for

243 the entire study area and for each zone using all on-effort visual and acoustic detections

244 divided by the total amount of good survey effort. All acoustic detections were included in 
245 the calculation of group encounter rate, but as only acoustically detected beaked whales

246 were identified to species with confidence only these were included in the calculation of

247 relative species diversity. Encounter rate variance and coefficient of variation (CV) was

248 determined as described by Buckland et al. (2001).

250 2.4.2. Existing information and opportunistic data on cetaceans

251 Existing information on cetaceans was collated by: examining museum collections;

252 identifying cetacean skeletal remains displayed in hotels, scuba-diving centres, and in

253 coastal communities; searching libraries for published and unpublished information;

254 gathering cetacean sighting reports from dive centres, sport fishers, tourists, sailors, etc.;

255 collating sightings from Marine Mammal Observers (MMOs) on seismic survey vessels

256 and from unpublished coastal dolphin surveys. Records were entered in a database

257 provided there were good quality supporting photographs to allow verification of the

258 species. Bottlenose dolphin sightings that could not be identified to species were retained

259 as Tursiops spp. All other records for which the species could not be identified, that did not

260 have a location of origin or that were outside the study area were excluded. The number of

261 species present, and the number of records of each species were determined for each zone.

262 2.5. Rapid Assessment of Threats to Cetaceans

263 The assessment evaluated the threats to cetaceans that are most ubiquitous; temporary or

264 localized threats (e.g. dolphin tourism, seismic surveys, point sources of pollution) were not

265 considered. Four primary threats were the focus of the evaluation: 1. cetacean mortality in

266 fishing gear, which comprised two factors: the bycatch rate and the size of the fleet; 2. 
267 cetacean hunting, consumption or use by humans; 3. shipping related collision risk and

268 noise disturbance; and 4. dynamite fishing. Data on each potential threat were either

269 generated for this study (bycatch, dynamite fishing, consumption, hunting) or were

270 compiled using existing information that could act as a proxy (shipping and size of fishing

271 fleet) (Table 1). Each threat was evaluated as described in the sections below.

272 Each of the threats was normalized on a scale of 0-100 based on rates (e.g., boats per km)

273 with the zone with the highest rate set to 100 and other zones scaled accordingly. An

274 overall potential threat score for each zone was the sum of these values with higher scores

275 representing a greater potential for human impact on cetaceans and a lower score indicating

276 lower threat levels. The objective was to assess relative potential risk to cetaceans in

277 relation to two metrics: relative cetacean abundance and relative species richness (number

278 of species recorded) for each zone sampled. Although the evaluated threats are unlikely to

279 have equal potential impact and some are likely to interact, in the absence of any

280 information on which to base a weighted or cumulative impact score, we consider them to

281 be of equal potential impact, while acknowledging that this is simplified and may omit

282 differences in the severity of threats.

284 2.5.1. Cetacean bycatch, hunting and consumption

285 Fisher interviews were conducted to collect information on marine mammal bycatch,

286 hunting, consumption and use. The rapid bycatch assessment questionnaire developed by

287 Moore et al. (2010) was used, and interviews were conducted in Swahili, one-on-one with

288 fishermen at fish landing sites. Gillnet fishers were the primary target of the interviews 
289 because this gear type has by far the highest bycatch rates for marine megafauna globally 290 and in the Western Indian Ocean (Kiszka et al., 2009). However long-line, purse-seine and 291 hook and line fisheries also kill cetaceans and as a secondary priority smaller numbers of 292 fishers that used these gears were also interviewed. Time and budget allowed for 293 approximately 5\% of the mainland fishing fleet to be interviewed (Ministry of Livestock 294 Development and Fisheries, 2010). The target was to collect 15 interviews from each 295 village and two villages in each district. It was not possible to select villages randomly 296 because in many there were no gillnetters. As recommended by Moore et al. (2010) the 297 most experienced fishermen and captains were targeted as they were likely to have most 298 knowledge. Only one fisher per vessel was interviewed, and it was assumed that this 299 provided an estimate of per-boat catch. Illustration cards were shown to help fishers 300 identify species. Marine mammals are legally protected in Tanzania so interviewees were 301 assured anonymity, and questions regarding hunting, catch, use, consumption and sale 302 included questions about how others in near-by communities use marine mammals to 303 increase the chances of receiving reliable responses. 304 305 2.5.2. Dynamite fishing

306 The cetacean acoustic survey described above also recorded 318 blast fishing explosions 307 during a total of 231 hours of recording along the entire Tanzanian coast (see Braulik, 308 Wittich, et al., 2015 for details of analysis). The blast data were analysed to calculate the 309 number of blasts per hour in each zone. 
311 2.5.3. Shipping related threats

312 As a broad-scale approximation of the potential for shipping related threats to impact

313 cetaceans, the total amount of goods brought by ship into ports located within each zone

314 was used as a proxy (Tanzania Ports Authority, 2015).

315 3. Results

316 3.1. Cetacean Habitat

317 The southern portion of the Tanzanian coastline (Zone 5) between Kilwa and Mtwara has a

318 very narrow continental shelf, the depth drops off quickly down to more than $2000 \mathrm{~m}$ less

319 than $30 \mathrm{~km}$ from the coast. This zone has the deepest depths and the largest amount of slope

320 habitat; approximately $60 \%$ of the area is greater than $800 \mathrm{~m}$ deep and has a sloping seabed

321 of more than $5^{\circ}$ (Figure $1 \& 2$ ). Similarly, Zone 3 around Dar es Salaam has a narrow

322 continental shelf, but the majority of the habitat includes intermediate depth primarily

323 ranging from $100-800 \mathrm{~m}$. In contrast, the Zanzibar channel (Zone 2) is almost exclusively

324 shallow water, with $94 \%$ of the habitat less than $100 \mathrm{~m}$ deep with a relatively flat bottom.

325 In the Rufiji Delta and Mafia (Zone 4) approximately $70 \%$ of the habitat is less than $100 \mathrm{~m}$

326 deep, but there are also some deeper zones east and south of Mafia Island. Finally, the

327 Pemba Channel (Zone 1) is intermediate in terms of depth and slope habitat; approximately

$32830 \%$ of the area is less than $100 \mathrm{~m}$ deep and the remaining $70 \%$ is between $100-800 \mathrm{~m}$.

329 Thirty percent of this zone including slopes $>5^{\circ}$. A notable feature of the Pemba Channel is

330 that it has a rapid consistent northward flowing current and is shaped like a trough,

331 somewhat similar to a submarine canyon with steep drop offs from 50-700m on either side

332 separated by approximately $40 \mathrm{~km}$ (Figure $1 \& 2$ ). 
333

334

335

336

337

338

339

340

341

342

343

344

345

346

347

348

349

350

351

352

353

354

\subsection{Rapid Assessment of Cetacean Communities}

\subsubsection{Vessel-based cetacean survey}

Over 34 days in March and April 2015, 2616 km of visual boat-based survey effort was conducted. Weather was acceptable for the majority of the survey; $90.5 \%(2368 \mathrm{~km})$ was in sea conditions of Beaufort 4 or less, and 75.5\% (1974km) in Beaufort 3 or less. Sighting rates in Beaufort 4 (1.5 groups/ 100km) were less than half those in Beaufort 1 (3.7 groups/ $100 \mathrm{~km})$. The towed acoustic array was deployed during 32 survey days collecting $216 \mathrm{~h}$ of recordings, and the SoundTrap data totalled $237 \mathrm{~h}$ of recordings.

In total, 75 marine mammal groups of 11 species were sighted (Table 2). Most acoustic detections coincided with visual encounters. However, 11 groups of delphinids and five groups of ziphiids identified in the acoustic data had no associated visual sighting. This takes the total combined number of cetacean groups detected during the survey using both visual and acoustic methods to 91 (Table 2). The cetacean community was mostly composed of delphinids, but also included several large odontocetes, including beaked whales (Ziphiidae) and the short-finned pilot whale (Globicephala macrorhynchus). The most frequently encountered species was the spinner dolphin, followed by Risso's dolphin, Indo-Pacific bottlenose and common bottlenose dolphins. Indian Ocean humpback dolphins were sighted in shallow near-shore waters less than 30m deep close to Kilwa and along the mainland coast of the Zanzibar Channel. One mixed species group of short-finned pilot whales with Fraser's dolphins (Lagenodelphis hosei), and several of Indo-Pacific bottlenose dolphins with Indian Ocean humpback dolphins were observed (Table 2). A single sighting of two dugongs (Dugong dugon) was made north of Mafia Island. 
355 Of the 75 visually detected groups, 12 were made when the acoustic array was not

356 deployed. Of the remaining 63 sightings, all but four groups were also detected

357 acoustically. A total of 19 groups consisting primarily of Risso's dolphins, Indian Ocean

358 bottlenose dolphins, and unidentified species, were detected acoustically based only on

359 clicks, with no whistles recorded. There were five acoustic detections of beaked whales

360 which did not have an associated visual sighting. The peak click frequency for each was

361 between 31 and $35 \mathrm{kHz}$ which is consistent with identification as Blainville's beaked whale

362 (Johnson, Madsen, Zimmer, de Soto, \& Tyack, 2006). One detection had a secondary peak

363 at $40 \mathrm{kHz}$, therefore this was identified as a probable Blainville's beaked whale but it is

364 possible it was a Cuvier's beaked whale (Ziphius cavirostris) (Baumann-Pickering et al.,

365 2013), or another species whose vocalizations have yet to be characterized (Table 2).

366 Restricting data to sea conditions of Beaufort 4 or less resulted in $2368 \mathrm{~km}$ of effort and the

367 inclusion of 77 sightings (63 visual, and 14 acoustic). The proportion of survey effort

368 conducted in different sea conditions was similar in all zones, but weather was slightly

369 better than average in Zones 2 and 3, and slightly poorer in Zone 5 (Figure 2). By far the

370 highest number of species (nine), and relative species diversity were recorded in Zone 1 -

371 the Pemba Channel, and this area also had high group encounter rate and the highest

372 individual encounter rate (Table 3; Figure 3). Low species encounter rates, number of

373 species and relative abundance were recorded in Zone 2, the Zanzibar Channel, where only

374 small groups of Indo-Pacific bottlenose and Indian Ocean humpback dolphins were

375 recorded. Very few cetaceans were encountered in Zone 4 - Mafia / Rufiji. Zone 5 -

376 Mtwara/Lindi had the highest group encounter rate of any zone, but relatively low diversity 
377 indices with sightings dominated by spinner and Risso's dolphins. Differences between

378 zones are accentuated when individual encounter rates are compared, because the two

379 zones with the highest group encounter rates (1 \& 5) also had large numbers of spinner

380 dolphins that occur in large groups (Table 3). The two most commonly encountered

381 cetacean species were different in every zone (Table 3). To investigate whether changing

382 our definition of good survey conditions would have changed these results, we examined

383 encounter rates by zone over a range of sea states (Figure 4). Irrespective of sea conditions,

384 the same two zone ( 1 and 5) had the highest encounter rates, and the same two zones ( 3 and

385 4) had comparatively lower encounter rates.

386 The mean classification rate of the whistle classifier was $60 \%$. This is lower than some other

387 comparable studies e.g. (Erbs et al., 2017), likely driven by the low sample sizes in the training

388 datasets. However, for initial assessment purposes it was acceptable. Classification accuracy was

389 highest for false killer whales (87.5\%) and spinner dolphins (69.2\%). It performed poorly

390 for pilot whales $(38.0 \%)$ and pantropical spotted dolphins $(36.8 \%)$ and intermediate for the

391 remaining two species. Insufficient whistles were recorded from any of the unidentified

392 visual sightings to enable their input into the whistle classifier. There were 11 acoustic

393 detections that had no accompanying visual sighting; of these, eight were classified as

394 spinner dolphins, and the remaining three were classified as two species or as one of the

395 species for which the classifier performed poorly. Because of the low certainty of the

396 resulting species classifications, all acoustic only delphinid whistle detections were

397 included in analysis as unidentified species.

398 3.2.2. Existing information and opportunistic data on cetaceans 
399 In total, 406 records of marine mammal sightings, strandings, and skeletal material were

400 compiled, comprising 20 stranded animals, 43 skeletal remains and 339 live sightings.

401 Fourteen species were represented in the data, but $80 \%$ of the records were of five species:

402 - Spinner dolphin $(\mathrm{n}=126 ; 31 \%$ of all records $)$

403 - Humpback whale $(\mathrm{n}=61 ; 15 \%)$

404 - Indo-Pacific bottlenose dolphin ( $=56 ; 14 \%)$

405 - Indian Ocean humpback dolphin $(\mathrm{n}=41 ; 10 \%)$;

406 - Risso's dolphin $(\mathrm{n}=35 ; 9 \%)$.

407 Three species in the qualitative data had not been seen during the vessel-based survey.

408 These were common dolphin (Delphinus delphis) and dwarf sperm whale (Kogia sima)

409 both recorded in the Pemba Channel. Humpback whales were absent from Tanzania at the

410 time of the boat survey but were documented from every zone in the qualitative data. This

411 takes the total number of documented species in the entire assessment to twelve. Once

412 humpback whales are removed from the data, the species with the largest number of

413 qualitative records in each zone, is the same as the species most frequently encountered

414 during the boat-based survey (Table 3).

416 3.3. Rapid assessment of threats to cetaceans

417 3.3.1. Cetacean bycatch

418 In total, 573 interviews were conducted, comprising 296 interviews from 31 villages in all

419 four regions of the Tanzanian mainland coast and 277 interviews from 12 villages in Pemba

420 and Unguja (Figure 1). By zone the number of interviews were as follows: 1 - 270; 2 - 147; 
$4213-22 ; 4-78 ; 5-56$. The average age of respondents was 43 years $(\mathrm{SD}=13)$, and was

422 similar (ranging between 37 and 45 years) in all regions. A total of $71 \%(n=407)$ of

423 interviews were with fishermen who used gillnets as their primary gear type and another

$424 \quad 10 \%$ used gillnets as their secondary gear type. Remaining interviews were with hook and

425 line $(11 \%, n=66)$, purse-seine $(8 \%, n=47)$, longline $(5 \%, n=27)$, trap $(4 \%, n=21)$ and

426 octopus spear fishers $(1 \%, \mathrm{n}=5)$. Of those interviewed, 95\% were full-time fishers, and just

427 over half also had another source of income with agriculture the most common (37\%). Boat

428 captains constituted $63 \%$ of respondents, while the remaining $37 \%$ were crew. Outboard

429 motors were present on $29 \%$ of the boats used by interviewees, and the remaining $71 \%$

430 were oar or sail powered.

431 Close to two-thirds of fishers (59\%) believed that there was only one type of dolphin in

432 Tanzania. Due to uncertainty in species identification by fishermen an overall cetacean

433 bycatch rate is provided rather than species specific rates.

434 A total of $17.4 \%$ of gillnetters reported that they had caught dolphins in the last calendar

435 year. Based on this an estimated national bycatch rate of 0.17 dolphins / gillnet boat / year

436 was calculated. The zone with the highest reported bycatch rate was Zone 1 - Pemba

437 Channel, with 0.24 dolphins / gillnet boat / year, almost five times higher than the lowest

438 reported rates in Zones 3 and 4, Dar es Salaam and Mafia/Rufiji, which were 0.05 and 0.04

439 dolphins / boat / year, respectively. In general, the bycatch rate on the islands of Pemba

440 and Unguja, collectively 0.24 dolphins / gillnet boat / year, was two and half times greater

441 than from the mainland Tanzania coast (0.10 dolphins / gillnet boat / year). Because few

442 interviews were conducted with fishers that use gear other than gillnets we note only that 
443 these limited data suggest that cetacean bycatch rates in purse-seines, longlines and with

444 hook and line were much lower than gillnets.

445 3.3.2. Cetacean hunting, consumption and use

446 Fishers were asked during interviews the fate of dolphins that were caught in a fishing net.

447 Perhaps reflecting reluctance at admitting knowledge about an illegal activity, $50 \%$ of

448 respondents did not answer the question. Of the remainder who did answer, $43 \%$ said the

449 animals were either released alive or discarded dead, 37\% said that dolphins were eaten,

$45014 \%$ that they were used as bait for sharks in the longline fishery, and $4 \%$ that the flesh was

451 rotted and the oil then used as a wood preservative for boats. The proportion of fishers that

452 reported eating dolphins was highest on Pemba (46\%) and in Zone 4 Mafia/Rufiji (50\%).

453 Of a total of 55 fish vendors interviewed, only one, who was from Ziwani on Pemba,

454 asserted that he had sold dolphin meat in the market recently. The meat was only rarely

455 available and was sold for the comparatively small sum of \$7.5-\$10 / whole dolphin. No

456 definitive evidence that dolphins were directly hunted was obtained.

457 3.3.3. Dynamite Fishing

458 Zone 3 - Dar es Salaam had an average blast fishing rate of 5.3 explosions / hour, which is

459 approximately seven times higher than anywhere else along the Tanzanian coast. With an

460 average of 1.4 blasts / hour, Zone 2 - Zanzibar Channel was the second most greatly

461 impacted zone, and all other areas blast rate was relatively low (Braulik, Wittich, et al., 462 2015).

463 3.3.4. Shipping 
464 Dar es Salaam is by far the biggest port in Tanzania; in 2014, it was visited by just over

4651000 ships, and handled 93\% of the country’s ocean cargo traffic: approximately 14.3

466 million tons (Tanzania Ports Authority, 2015). Ships typically approach from the wider

467 Indian Ocean and do not travel extensively along the Tanzanian coast, therefore Zone 3 -

468 Dar es Salaam is likely to be most extensively affected by shipping related noise and

469 disturbance. Much smaller ports in Tanga and Mtwara each handle about 0.36 Million tons

470 per year $(\sim 2.4 \%$ each of the national total) and Zanzibar 0.15 Million tons per year

471 (Zanzibar Ports Corporation). One of the busiest high-speed ferry routes in East Africa runs

472 between Zanzibar and Dar es Salaam, therefore disturbance, underwater noise and the

473 potential for marine mammal - ship strikes is moderate in Zone 2.

$474 \quad 3.3 .5$. Overall threat evaluation

475 Information on dolphin hunting and consumption was equivocal and so this potential threat

476 was not included in the overall score. The zone with the highest overall potential threats to

477 cetaceans was assessed to be Zone 3 - Dar es Salaam which is influenced by the major port

478 as well by the very high prevalence of blast fishing (Table 4; Figure 5). By contrast

479 cetaceans in Zone 1, the Pemba Channel are also evaluated as being under higher potential

480 threat than other areas, but here they are subject to fisheries related impacts with higher

481 estimated dolphin bycatch rates and total number of gillnets.

482 4. Discussion

483 4.1. Conservation Priorities for Cetaceans in Tanzania

484 This assessment demonstrated considerable cetacean diversity in Tanzania as well as

485 substantial variation in cetacean relative abundance and diversity along the coast. Three 
486 new mammal records; Blainville's beaked whale, dwarf sperm whale and common dolphin

487 (seen in the wild by GTB \& MK and verified with good quality photographs) were

488 documented taking the total number of cetaceans confirmed in Tanzania from 16 (Amir et

489 al., 2012) to 19. Cetacean abundance indices were highest in the two deepest parts of the

490 coast (Zone 1 - Pemba Channel and Zone 5 - Mtwara), almost double those of the shallower

491 areas (Zone 2 and 4). Higher diversity and abundance of cetaceans in areas with a greater

492 variety of depth and slope habitat is typical and is related to increased mixing of nutrient

493 rich waters which increases productivity and prey availability (Cañadas et al., 2002;

494 Hooker, Whitehead, \& Gowans, 1999).

495 Based on this study, with high relative cetacean abundance and diversity, we consider the

496 Pemba Channel (Zone 1) in the north of Tanzania to be the most important area for

497 cetaceans nationally. A total of 16 of the 19 cetacean species known to occur in Tanzania

498 have been documented from this location, including the endangered Indian Ocean

499 humpback dolphin. The channel between the Tanzanian mainland and Pemba island is only

$50050 \mathrm{~km}$ wide but it is $1000 \mathrm{~m}$ deep, and has bathymetric features similar to submarine

501 canyons which are well known as important areas for cetaceans (Moors-Murphy, 2014).

502 There is a fast $(0.5-3 \mathrm{~m} / \mathrm{s})$ north-flowing current, and the turbulence and vertical mixing that

503 occurs along the margins of the channel create nutrient-rich conditions (Barlow et al., 2011;

504 Mahongo \& Shaghude, 2014). This type of mixing, which is common adjacent to tropical

505 islands, can provide oases of biodiversity in otherwise nutrient-poor tropical oceans

506 (Kiszka, Ersts, \& Ridoux, 2010). The Pemba Channel was recently identified as an

507 Ecologically and Biologically Significant Area (EBSA) by the Convention on Biological 
508 Diversity (2013) and it is renowned for catches of large pelagic fish (Hemphill, 1995). Even 509 though there are marine protected areas (MPAs) along the Tanga and Pemba coastlines, our 510 assessment suggests that the Pemba Channel is also subject to relatively high levels of 511 potential threat, from bycatch in fishing gear and dynamite fishing. Therefore, from the 512 perspective of cetaceans we conclude that this location is the priority for future research 513 and conservation (Figure 5).

514 The Rufiji delta (Zone 4) is one of the largest estuaries and mangrove stands on the east 515 coast of Africa, and harbours the only remaining population of dugong in Tanzania (Muir, 516 Sallema, Abdallah, De Luca, \& Davenport, 2003), whale sharks (Rhincodon typus) (Cagua 517 et al., 2015) and large numbers of nesting sea turtles (Bourjea, Nel, Jiddawi, Koonjul, \& 518 Bianchi, 2008). The same issues, principally fisheries bycatch, threaten all these 519 endangered species and conservation actions on behalf of one are likely to benefit all.

520 Mtwara/Lindi (Zone 5) in southern Tanzania is the least developed part of the country's 521 coastline. It was evaluated as the area with the lowest relative potential threat to cetaceans, 522 and the area of highest cetacean relative abundance. Cetacean communities recorded were 523 dominated by spinner and Risso's dolphins, both species that preferentially occur on the 524 margins of the continental shelf (Jefferson et al., 2014; Perrin, 2009). This area is a focus 525 of exploration and extraction of oil and gas and, given the high relative abundance of 526 cetaceans and the presence of species that are known to be sensitive to anthropogenic 527 sound, such as beaked whales and also humpback whales, it is important that potential 528 impacts of these activities be carefully evaluated and mitigated (Cerchio, Strindberg, 529 Collins, Bennett, \& Rosenbaum, 2014; Southall et al., 2009). 
530 It is important to note that the east coast of Pemba and Zanzibar, and offshore waters

531 beyond $50 \mathrm{~km}$ from the mainland coast, were not included in the study area and it is

532 probable that additional areas within Tanzanian waters that were not surveyed may be

533 important for marine mammals. Two areas that are high priority to investigate because of

534 potential small-scale upwelling are the east coast of Pemba and the sea mount located due

535 east of Pemba in 2000m of water (Mahongo \& Shaghude, 2014).

536 Indian Ocean humpback and Indo-pacific bottlenose dolphins occur predominantly in

537 shallow coastal areas. This near-shore distribution places them in the marine waters most

538 heavily utilized by humans (Keith, Atkins, Johnson, \& Karczmarski, 2013; Stensland,

539 Carlen, Sarnblad, Bignert, \& Berggren, 2006). Throughout their range, both species are

540 threatened by bycatch in fishing gear, coastal development and pollution, and in Tanzania

541 they are also exposed to the noise and physical threat of dynamite fishing. The Indian

542 Ocean humpback dolphin which has the most near-shore distribution of the two, is thought

543 to be the most threatened cetacean in the region (Braulik, Findlay, Cerchio, \& Baldwin,

544 2015). Indian Ocean humpback dolphins appear to have a discontinuous distribution along

545 the Tanzanian coast with concentrations in large shallow areas, including on both sides of

546 the Zanzibar and Pemba channels (Zone 1 and 2), and in the Rufiji Delta (Zone 4).

547 Although they may occur along the $200 \mathrm{~km}$ stretch of coast between Kilwa and Mtwara, no

548 evidence of their presence was found during surveys and the available shallow habitat

549 along that exposed coastline is extremely limited. As one of the most threatened marine

550 megafauna species regionally, conservation of Indian Ocean humpback dolphins should be

551 a national priority. Humpback whales are present in Tanzania in considerable numbers 
552 from June to November, but they are also regularly entangled in drift gillnets (Amir et al., 553 2012). All three of these cetacean species are potentially under pressure from fisheries 554 bycatch and habitat degradation, and it is important to generate information on areas of 555 concentration, residency, movement and connectivity, as well as abundance, in order that 556 key areas may be identified and protected. It is important to note that there can be 557 considerable population structure within cetaceans, and potentially other more pelagic 558 species in Tanzania may well also be under threat. For example, in Hawaii, which is not 559 dissimilar tropical habitat to Tanzania, long-term research showed that there were small, 560 demographically isolated, island associated populations of false killer whales that were 561 declining rapidly due to bycatch in the longline fishery (Reeves, Leatherwood, \& Baird, 562 2009).

563

564 Fishing is the single largest threat to cetaceans worldwide with around 300,000 estimated 565 cetacean mortalities per year in fishing nets (Read, 2008). Fisheries interactions are also 566 likely to be the largest threat to cetaceans in Tanzania, with negative impacts arising from 567 direct entanglement, hooking on longlines, as well as potential disturbance and injury from 568 fishing with explosives (Kiszka et al., 2009). Marine fisheries operating in the study area in 569 Tanzania are artisanal and near-shore. They use a variety of gears to target multiple species 570 and the distinction between target and bycatch species is vague, especially as captured 571 dolphins can be utilized in many ways including as food, bait and oil. Cetaceans are legally 572 protected in Tanzania although this is rarely enforced and fines seldom imposed. Some

573 fishers did appear to express reluctance in discussing use of cetaceans, which may mean 574 that our calculated bycatch level has been underestimated. However, if biases are uniform 
575 across the country, the comparative levels of bycatch threat by zone should still be valid.

576 The interview-based bycatch rates reported here were similar to those reported from

577 Zanzibar in 1999 (0.46 dolphins/boat/year) (Amir, Berggren, \& Jiddawi, 2002). The

578 dolphin capture rates per boat are not high, however, there are estimated to be over 16,000

579 fishing vessels in the country and gillnets constitute about $35 \%$ of documented fishing gear

580 (Ministry of Livestock Development and Fisheries, 2010; Zanzibar Ministry of Livestock

581 and Fisheries, 2010), so the total number of dolphins captured in Tanzania is likely to be

582 considerable each year. As would be expected there is a loose correlation between the

583 recorded cetacean relative abundance in each zone and bycatch rate, with higher bycatch

584 rates recorded in areas with higher cetacean relative abundance. To know if these rates are

585 causing cetacean population declines it is necessary to understand the size of populations;

586 this information is currently lacking from most places in east Africa. However because

587 dolphins reproduce slowly, populations generally cannot sustain mortality rates greater than

588 a few percent of population size, and especially for small, coastal cetacean populations in

589 heavily fished areas mortality rates are frequently unsustainable (Read, 2008). This was

590 demonstrated during on-board observer programmes in Zanzibar, which estimated that

$5919.6 \%$ of the estimated population of Indo-Pacific bottlenose dolphins and $6.3 \%$ of Indian

592 Ocean humpback dolphins were taken as bycatch annually, rates which were unsustainable

593 based on abundance estimates for both species (Amir, 2010). Further investigation of

594 bycatch is a priority, focusing on understanding the effects of gear type and habitat on

595 capture levels, placing bycatch rates in context by estimating abundance of the most

596 frequently caught cetacean species and ultimately developing, implementing and

597 monitoring mitigation strategies. 
598

599 Many uses of accidentally captured dolphins in Tanzania were identified, including

600 consumption, but little commercial sale of the meat. Cetacean consumption is increasing

601 worldwide, and can quickly shift from occasional consumption of accidentally entangled

602 animals to intentional targeting and hunting (Cosentino \& Fisher, 2016). Pemba is the

603 main location where dolphins are known to be sold and regularly consumed and monitoring

604 of fish markets may reveal that consumption and sale is more common than suggested by

605 our interviews.

606 Tanzania is the only country in the Western Indian Ocean where fishing with explosives

607 has been widely practised for more than 50 years (Wells, 2009). The sound from a single

608 blast can travel up to $50 \mathrm{~km}$ from the source. With more than 70 blasts/day in some areas,

609 this represents considerable additional noise in the ocean (Braulik, Wittich, et al., 2015).

610 The majority of blast fishing occurs in coastal waters in the habitat of Indian Ocean

611 humpback and Indo-Pacific bottlenose dolphins and these species will be impacted to the

612 greatest extent, with effects ranging from abandoning heavily dynamited habitats, lost

613 feeding, socializing or resting opportunities, as well as the potential for physical injury

614 (including impaired hearing) and death at short range (McGregor, Horn, Leonard, \&

615 Thomsen, 2013). Blast fishing negatively impacts many aspects of the marine

616 environment; it is complex to combat, but a high priority to prevent.

617 4.2. Advantages and Disadvantages of Cetacean Rapid Assessment 
618 Marine mammals are much less well understood than their terrestrial mammal counter-

619 parts, whilst the level of threat they face is believed to be just as high (Schipper et al.,

620 2008). The number of species threatened with extinction far outstrips available

621 conservation resources, which places a premium on prioritization and the importance of

622 identifying and protecting 'biodiversity hotspots' (Myers, Mittermeier, Mittermeier, da

623 Fonseca, \& Kent, 2000). This rapid assessment is a useful and flexible approach to quickly

624 evaluate large areas of coastline and draw general conclusions about cetacean communities,

625 habitat and threats. This type of broad-scale, level-one rapid investigation which generates

626 community rather than species-specific information is appropriate because, from a

627 management perspective, while there are nuances in species-specific vulnerability,

628 essentially the same threats (e.g. fishing, underwater noise, habitat degradation, etc.) impact

629 all cetaceans to some degree, and therefore effective mitigation actions are likely to be very

630 similar for all species. In addition, using cetacean community encounter rates is a

631 quantitative metric that requires a much lower input of survey effort than generation of

632 species specific abundance estimates.

633

634 Using simple cetacean community encounter rates without accounting for variation in

635 detection probabilities among species in different surveying conditions, even when poor

636 weather is excluded, could introduce bias. Generally speaking, such encounter rates will be

637 dominated by species that are more visible, occur in larger groups and spend longer at the

638 surface. In addition, the impact on detection probability of the combined effects of wind

639 and swell are more apparent further from shore and in deep water. Thus, surveys in zones

640 with different habitats may be affected differentially by variable survey conditions. 
641 However, our results were consistent regardless of sea conditions (Figure 4). The

642 combination of a visual survey with an acoustic survey likely contributed to this

643 consistency, and it is important that future rapid assessments consider using acoustic

644 technology as well as visual surveys to minimise the impact of variable sea conditions on

645 cetacean community encounter rates, as well as comprehensively exploring the impact of

646 survey conditions on the conclusions.

647

648 In this survey, we were fortunate that cetacean encounter rates were relatively high

649 generating sufficient data to draw broad conclusions. The ratio of distance surveyed in good

650 conditions to area was between $0.06-0.07$ in every zone. This level of effort relative to area

651 worked well in the current assessment and could be used as a starting point when planning

652 future rapid assessments. However, in areas with lower encounter rates, or consistently

653 poor weather, a rapid assessment of cetaceans would be more challenging and may not

654 generate enough information to draw any meaningful conclusions without expending

655 considerably more survey effort.

656

657 A rapid assessment, as with almost all surveys, can confirm species presence, but it cannot

658 confirm species absence. A single survey will not capture temporal shifts in species

659 distribution and migratory species not present would also not be detected (e.g. in this

660 instance humpback whales but also possibly other seasonal species). Some rare and

661 uncommon species, arguably amongst the most important from a conservation perspective,

662 will also not have been documented. For example, humpback dolphins were not seen in

663 Zone 1 - Pemba, during this rapid assessment but were frequently observed during more 
664 intensive coastal surveys along both the Tanga and Pemba coasts. The use of a large

665 seaworthy catamaran enabled the survey to safely navigate offshore waters which was

666 important, but because of its draft we were restricted for safety reasons in our ability to

667 survey shallow areas $<20$ m deep which is where the majority of humpback dolphins are

668 found (Braulik, Findlay, et al., 2015). In areas with extensive shallows future rapid

669 assessments could deploy two different survey platforms, a larger seaworthy vessel for

670 offshore areas and a smaller shallower draft vessel for near-shore areas.

671 Care must be taken in the designation of zones for presenting the data. In this instance, it

672 worked well to split the study area into five zones based on depth, which also

673 coincidentally broadly matched the provincial boundaries, providing a biological and a

674 political rationale for presenting the information. In other applications, it will be equally

675 important to select zones based on habitat because this will influence the cetacean

676 community that is present.

677

678 The evaluation of threats in a rapid assessment is necessarily relatively superficial but to

679 evaluate threats comprehensively is complex. For example, Crain, Kroeker, \& Halpern

680 (2008) found that of the cumulative effects of multiple stressors in the marine environment,

$68126 \%$ were additive, $36 \%$ synergistic, and $38 \%$ antagonistic. The evaluation of potential

682 threats conducted here using coarse scale qualitative data provided a general indication of

683 the important issues, and their relative intensity. To develop effective mitigation of threats,

684 which can be complex and interacting, will require more in-depth studies. 
685 Whether completing a cetacean rapid assessment in one year is sufficiently quick for it to 686 be accurately termed 'rapid' depends upon your perspective. In comparison to some of the 687 targeted terrestrial or coral reef rapid assessments that may be completed in a matter of 688 months, this is slow, but given the large geographic scope and compared to the majority of 689 other marine mammal studies it can be considered rapid.

690 A strength of this approach is that it can be adapted to the local situation, particularly 691 regarding the use of different types of opportunistic data. In this assessment, very little 692 historical information was found in the literature, but a large quantity of data were 693 compiled from the dive and sport fishing operators. In other countries, the most useful 694 sources of historical or opportunistic data will vary, but it is important that all possible 695 avenues are explored. A rapid assessment is an initial investigation and it is important that 696 it is not seen as the end point or its results over interpreted. It is hoped that initial studies 697 such as these will act as a catalyst for more intensive targeted work that generates more 698 detailed species-specific information to capture temporal changes in distribution and 699 estimate abundance.

700 Despite the many caveats noted above, there is a place for rapid assessment of cetaceans as 701 a tool to provide important initial information about the marine environment and the threats 702 to species. This is a useful approach to quickly provide broad-scale information on relative 703 occurrence of common cetacean species across large data deficient areas that can be used to 704 target research needs and guide the development of management priorities.

705 Generating robust baseline data on marine mammal communities and threats at a wide 706 spatial scale is a critical first step to identifying and prioritizing species and locations that 
707 require urgent conservation action. This kind of information is vital to enable cetaceans to

708 be included in global and regional initiatives to identify important biodiversity areas, such

709 as EBSAs, Important Marine Mammal Areas (IMMAs), Key Biodiversity Areas (KBAs)

710 and MPAs and, similarly, to feed into the environmental impact assessment (EIA) process.

711 It can also be a useful first activity for researchers entering a new, unknown area, to

712 identify where to focus future intensive research. The baseline marine ecological

713 information generated is increasingly required by governments as they seek to meet the

714 target to protect $10 \%$ of their waters by 2020 , and to manage and reduce the impact of

715 burgeoning development, disturbance and use of the oceans.

716

717 5. Acknowledgements

718 We thank Kate Grellier, Albert Reichert, Randy Reeves, Simon Northridge, and Tim

719 Davenport for their help in getting this project off the ground. The crew of the yacht

720 Walkabout, Gerry Hallam and Sabina Montserrat, Laura Morse, Haji Mohammad Haji were

721 instrumental in the project success. We thank Matt Richmond, Mohammad Sharif, Omar

722 Amir, Hosea Mbilinyi, Lindsey West and Mwanaidi Mlolwa for their assistance and

723 guidance. Community interviews were conducted by Gumbo Majubwa and Nassoor Akida

724 Ally, and GIS analysis by Yussuf Said Yussuf and Yves Barthelemy. Helpful reviews of

725 the report were provided by Tim Davenport, Howard Rosenbaum, Gianna Minton, Nell

726 Hamilton and Robin Baird. The work was funded by the Pew Marine Fellows Program and

727 WCS.

728 6. References 
Alliance for Zero Extinction. (2003). Criteria for the Definition of Conservation Areas. Alliance for Zero Extinction. http://www.zeroextinction.org/criteria.html.

Alonso, L. E., Deichmann, J. L., McKenna, S. A., Naskrecki, P., \& Richards, S. J. (Eds.). (2011). Still Counting...: Biodiversity Exploration for Conservation - The First 20 Years of the Rapid Assessment Program. Arlington, VA, USA: Conservation International.

Amir, O. A. (2010). Biology, ecology and anthropogenic threats of Indo-Pacific bottlenose dolphins in east Africa. PhD Thesis. (PhD Thesis), Stockholm University, Sweden.

Amir, O. A., Berggren, P., \& Jiddawi, N. S. (2002). The incidental catch of dolphins in gillnet fisheries in Zanzibar, Tanzania. Western Indian Ocean Journal of Marine Science, 1(2), 155-162.

Amir, O. A., Berggren, P., \& Jiddawi, N. S. (2012). Recent records of marine mammals in Tanzanian waters. Journal of Cetacean Research and Management, 12(2), 249-253.

Barbour, M. T., Gerritsen, J., Snyder, B. D., \& Stribling, J. B. (1999). Rapid Bioassessment Protocols for Use in Streams and Wadeable Rivers: Periphyton, Benthic Macroinvertebrates and Fish, Second Edition. EPA 841-B-99-002. U.S. Environmental Protection Agency; Office of Water; Washington, D.C.

Barlow, R., Lamont, T., Kyewalyanga, M., Sessions, H., van den Berg, M., \& Duncan, F. (2011). Phytoplankton production and adaptation in the vicinity of Pemba and Zanzibar islands, Tanzania. African Journal of Marine Science, 33(2), 283-295. doi:10.2989/1814232X.2011.600430

Baumann-Pickering, S., McDonald, M. A., Simonis, A. E., Solsona Berga, A., Merkens, K. P. B., Oleson, E. M., . . . Hildebrand, J. A. (2013). Species-specific beaked whale echolocation signals. The Journal of the Acoustical Society of America, 134(3), 2293-2301. doi:doi:http://dx.doi.org/10.1121/1.4817832

Berggren, P. (2009). Whales and dolphins: A field guide to marine mammals of East Africa. . Norwich, UK: East Publishing Limited.

Bourjea, J., Nel, R., Jiddawi, N. S., Koonjul, M. S., \& Bianchi, G. (2008). Sea turtle bycatch in the West Indian Ocean: review, recommendations and research priorities. Western Indian Ocean Journal of Marine Science, 7(2), 137-150.

Bowen, W. D. (1997). Role of marine mammals in aquatic ecosystems. Marine Ecology Progress Series, 158, 267-274.

Braulik, G. T., Findlay, K., Cerchio, S., \& Baldwin, R. (2015). Chapter Five - Assessment of the Conservation Status of the Indian Ocean Humpback Dolphin (Sousa plumbea) Using the IUCN Red List Criteria. In T. A. Jefferson \& B. E. Curry (Eds.), Advances in Marine Biology (Vol. 72, pp. 119-141): Academic Press.

Braulik, G. T., Wittich, A., Macaulay, J., Kasuga, M., Gordon, J., Gillespie, D., \& Davenport, T. R. B. (2015). Fishing with explosives in Tanzania: spatial distribution and hotspots 19pp. Wildlife Conservation Society Tanzania Program. Zanzibar, Tanzania.

Buckland, S. T., Anderson, D. R., Burnham, K. P., Laake, J. L., Borchers, D. L., \& Thomas, L. (2001). Introduction to distance sampling: estimating abundance of biological populations. Oxford: Oxford University Press.

Cagua, E. F., Cochran, J. E., Rohner, C. A., Prebble, C. E., Sinclair-Taylor, T. H., Pierce, S. J., \& Berumen, M. L. (2015). Acoustic telemetry reveals cryptic residency of whale sharks. Biology letters, 11(4), 20150092. 
Cañadas, A., Sagarminaga, R., \& García-Tiscar, S. (2002). Cetacean distribution related with depth and slope in the Mediterranean waters off southern Spain. Deep-Sea Research Part 1, 49, 2053-2073.

Cerchio, S., Strindberg, S., Collins, T., Bennett, C., \& Rosenbaum, H. (2014). Seismic surveys negatively affect humpback whale singing activity off northern Angola. PLOS ONE, 9(3), e86464. doi:10.1371/journal.pone.0086464

Christiansen, F., Lusseau, D., Stensland, E., \& Berggren, P. (2010). Effects of tourist boats on the behaviour of Indo-Pacific bottlenose dolphins off the south coast of Zanzibar. Endangered Species Research, 11, 91-99.

Convention on Biological Diversity. (2013). Southern Indian Ocean regional workshop to facilitate the description of Ecologically or Biologically Significant Marine Areas, Mauritius.

Cosentino, A. M., \& Fisher, S. (2016). The utilization of aquatic bushmeat from small cetaceans and manatees in South America and West Africa. Frontiers in Marine Science, 3, 163.

Crain, C. M., Kroeker, K., \& Halpern, B. S. (2008). Interactive and cumulative effects of multiple human stressors in marine systems. Ecology Letters, 11(12), 1304-1315.

Davidson, A. D., Boyer, A. G., Kim, H., Pompa-Mansilla, S., Hamilton, M. J., Costa, D. P., . . Brown, J. H. (2011). Drivers and hotspots of extinction risk in marine mammals. PNAS, www.pnas.org/cgi/doi/10.1073/pnas.1121469109.

Erbs, F., Elwen, S. H., \& Gridley, T. (2017). Automatic classification of whistles from coastal dolphins of the southern African subregion. The Journal of the Acoustical Society of America, 141(4), 2489-2500.

Fennessy, M. S., Jacobs, A. D., \& Kentula, M. E. (2007). An evaluation of rapid methods for assessing the ecological condition of wetlands. Wetlands, 3, 543-560.

Ferretti, F., Worm, B., Britten, G. L., Heithaus, M. R., \& Lotze, H. K. (2010). Patterns and ecosystem consequences of shark declines in the ocean. Ecology Letters, 13(8), 1055-1071.

Gillespie, D., Caillat, M., Gordon, J., \& White, P. (2013). Automatic detection and classification of odontocete whistles. The Journal of the Acoustical Society of America, 134(3), 2427-2437. doi:doi:http://dx.doi.org/10.1121/1.4816555

Gillespie, D., Gordon, J., Mchugh, R., McLaren, D., Mellinger, D. K., Redmond, P., . . . Deng, X. Y. (2008). Pamguard: semiautomated, open source software for real-time acoustic detection and localisation of cetaceans. Proceedings of the Institute of Acoustics, 30(5), 9pp.

Gruden, P., White, P. R., Oswald, J. N., Barkley, Y., Cerchio, S., Lammers, M., \& Baumann-Pickering, S. (2016). Differences in oscillatory whistles produced by spinner (Stenella longirostris) and pantropical spotted (Stenella attenuata) dolphins. Marine Mammal Science, 32(2), 520534. doi:10.1111/mms.12280

Heithaus, M. R., Frid, A., Wirsing, A. J., \& Worm, B. (2008). Predicting ecological consequences of marine top predator declines. Trends in Ecology \& Evolution, 23(4), 202-210. doi:http://dx.doi.org/10.1016/i.tree.2008.01.003

Hemphill, S. (1995). The ecology and exploitation of yellowfin tuna, Thunnus albacares (Bonnaterre 1788) in the Pemba Channel, Kenya. PhD Thesis. (PhD), University of Wales, Bangor.

Hobday, A., Smith, A., Stobutzki, I., Bulman, C., Daley, R., Dambacher, J., . . F Furlani, D. (2011). Ecological risk assessment for the effects of fishing. Fisheries Research, 108(2), 372-384.

Hooker, S. K., Whitehead, H., \& Gowans, S. (1999). Marine Protected Area Design and the Spatial and Temporal distribution of cetaceans in a submarine canyon. Conservation Biology, 13(3). 
IUCN. (2015). IUCN Red List of Threatened Species. version 2015.4: <http://www.iucnredlist.org> Downloaded on 26 January 2016.

Jefferson, T. A., Weir, C. R., Anderson, R. C., Ballance, L. T., Kenney, R. D., \& Kiszka, J. J. (2014). Global distribution of Risso's dolphin Grampus griseus: a review and critical evaluation. Mammal Review, 44(1), 56-68. doi:10.1111/mam.12008

Jewell, R., Thomas, L., Harris, C., Kaschner, K., Wiff, R., Hammond, P. S., \& Quick, N. J. (2012). Global analysis of cetacean line-transect surveys: detecting trends in cetacean density. Marine Ecology Progress Series, 453, 227-240. doi:10.3354/meps09636

Johnson, M., Madsen, P. T., Zimmer, W. M. X., Aguilar de Soto, N., \& Tyack, P. L. (2004). Beaked whales echolocate on prey. Proceedings of the Royal Society of London B: Biological Sciences, 271(Suppl 6), S383-S386. doi:10.1098/rsbl.2004.0208

Johnson, M., Madsen, P. T., Zimmer, W. M. X., de Soto, N. A., \& Tyack, P. L. (2006). Foraging Blainville's beaked whales (Mesoplodon densirostris) produce distinct click types matched to different phases of echolocation. Journal of Experimental Biology, 209(24), 5038-5050. doi:10.1242/jeb.02596

Kaschner, K., Quick, N., Jewell, R., Williams, R., \& Harris, C. M. (2012). Global coverage of cetacean line-transect surveys: status quo, gaps and future challenges. PLOS ONE, 7(9): e44075. doi:10.1371/journal.pone.0044075.

Kaschner, K., Tittensor, D. P., Ready, J., Gerrodette, T., \& Worm, B. (2011). Current and future patterns of global marine mammal biodiversity. PLOS ONE, 6(5), e19653.

Keith, M., Atkins, S., Johnson, A. E., \& Karczmarski, L. (2013). Area utilization patterns of humpback dolphins (Sousa plumbea) in Richards Bay, KwaZulu-Natal, South Africa. Journal of Ethology, 31(3), 261-274. doi:10.1007/s10164-013-0375-z

Kiszka, J., Ersts, P., \& Ridoux, V. (2010). Structure of a toothed cetacean community around a tropical island (Mayotte). African Journal of Marine Science, 32(3), 543-551.

Kiszka, J., Muir, C., Poonian, C., Cox, T. M., Amir, O. A., Bourjea, J., . . Bristol, N. (2009). Marine mammal bycatch in the southwest Indian Ocean: Review and need for a comprehensive status assessment. Western Indian Ocean Journal of Marine Science, 7(2), 119-136.

Lewison, R. L., Crowder, L. B., Read, A. J., \& Freeman, S. A. (2004). Understanding the impact of fisheries bycatch on marine megafauna. Trends in Ecology and Evolution, 19(11), 598-604.

Madsen, P. T., Carder, D., Bedholm, K., \& Ridgway, S. (2005). Porpoise clicks from a sperm whale nose-Convergent evolution of $130 \mathrm{kHz}$ pulses in toothed whale sonars? Bioacoustics, 15(2), 195-206.

Mahongo, S. B., \& Shaghude, Y. W. (2014). Modelling the dynamics of the Tanzanian coastal waters. Journal of Oceanography and Marine Science, 5(1), 1-7.

Mannocci, L., Catalogna, M., Dorémus, G., Laran, S., Lehodey, P., Massart, W., . . . Ridoux, V. (2014). Predicting cetacean and seabird habitats across a productivity gradient in the South Pacific gyre. Progress in Oceanography, 120(0), 383-398. doi:http://dx.doi.org/10.1016/j.pocean.2013.11.005

Maragos, J. E., \& Cook, C. W. (1995). The 1991-1992 rapid ecological assessment of Palau's coral reefs. Coral Reefs, 14(4), 237-252. doi:10.1007/BF00334348

Maragos, J. E., Potts, D. C., Aeby, G. S., Gulko, D., Kenyon, J., Siciliano, D., \& VanRavenswaay, D. (2004). 2000-2002 Rapid Ecological Assessment of Corals (Anthozoa) on Shallow Reefs of the Northwestern Hawaiian Islands. Part 1: Species and Distribution. Pacific Science, 58(2), 211-230. 
McGregor, P., Horn, A., Leonard, M., \& Thomsen, F. (2013). Anthropogenic Noise and Conservation. In H. Brumm (Ed.), Animal Communication and Noise (Vol. 2, pp. 409-444): Springer Berlin Heidelberg.

Mellinger, D. K., Thode, A. M., \& Martinez, A. (2002). Passive acoustic monitoring of sperm whales in the Gulf of Mexico, with a model of acoustic detection distance. Proceedings of the Twenty-first annual Gulf of Mexico information transfer meeting, 493-501.

Ministry of Livestock Development and Fisheries. (2010). Marine Fisheries Frame Survey Results 2009. Government of the United Republic of Tanzania.

Moore, J. E., Cox, T. M., Lewison, R. L., Read, A. J., Bjorkland, R., McDonald, S. L., . . Kiszka, J. (2010). An interview-based approach to assess marine mammal and sea turtle captures in artisanal fisheries. Biological Conservation, 143, 795-805.

Moors-Murphy, H. B. (2014). Submarine canyons as important habitat for cetaceans, with special reference to the Gully: A review. Deep Sea Research Part II: Topical Studies in Oceanography, 104(0), 6-19. doi:http://dx.doi.org/10.1016/i.dsr2.2013.12.016

Muir, C. E., Sallema, A., Abdallah, O., De Luca, D., \& Davenport, T. R. B. (2003). The dugong (Dugong dugon) in Tanzania: A national assessment of status, distribution and threat. 31pp. Wildlife Conservation Society.

Myers, N., Mittermeier, R. A., Mittermeier, C. G., da Fonseca, G. A. B., \& Kent, J. (2000). Biodiversity hotspots for conservation priorities. Nature, 403(6772), 853-858. doi:http://www.nature.com/nature/journal/v403/n6772/suppinfo/403853a0 S1.html

Perrin, W. F. (2009). Spinner dolphin Stenella longirostris. In W. F. Perrin, B. Würsig, \& J. G. M. Thewissen (Eds.), Encyclopedia of Marine Mammals. Second Edition (pp. 1100-1103): Academic Press.

Pompa, S., Ehrlich, P. R., \& Ceballos, G. (2011). Global distribution and conservation of marine mammals. PNAS, 108(33), 13600-13605.

QGIS Development Team. (2016). QGIS Geographic Information System. Open Source Geospatial Foundation Project. http://qgis.osgeo.org.

Read, A. J. (2008). The looming crisis: interactions between marine mammals and fisheries. Journal of Mammalogy, 89(3), 541-548.

Redfern, J. V., Ferguson, M. C., Becker, E. A., Hyrenbach, K. D., Good, C., Barlow, J., . . Werner, F. (2006). Techniques for cetacean-habitat modelling. Marine Ecology Progress Series, 310, 271-295.

Reeves, R. R., Leatherwood, S., \& Baird, R. W. (2009). Evidence of a possible decline since 1989 in false killer whales (Pseudorca crassidens) around the main Hawaiian Islands. Pacific Science, 63, 253-261.

Roch, M. A., Scott Brandes, T., Patel, B., Barkley, Y., Baumann-Pickering, S., \& Soldevilla, M. S. (2011). Automated extraction of odontocete whistle contours. The Journal of the Acoustical Society of America, 130(4), 2212-2223. doi:doi:http://dx.doi.org/10.1121/1.3624821

Schipper, J., Chanson, J. S., Chiozza, F., Cox, N. A., Hoffman, M., Katariya, V., . . . Young, B. E. (2008). The status of the world's land and marine mammals: diversity, threat, and knowledge. Science, 322, 225-230.

Southall, B., Berkson, J., Bowen, D., Brake, R., Eckman, J., Field, J., . . . Winokur, R. (2009). Addressing the effects of human-generated sound on marine life: an integrated research plan for U.S. federal agencies. 72pp. Interagency task force on anthropogenic sound and 
the marine environment of the joint subcommittee on ocean science and technology. Washington DC.

Stensland, E., \& Berggren, P. (2007). Behavioural changes in female Indo-Pacific bottlenose dolphins in response to boat-based tourism. Marine Ecology Progress Series, 332, 225-234.

Stensland, E., Carlen, I., Sarnblad, A., Bignert, A., \& Berggren, P. (2006). Population size, distribution, and behavior of Indo-pacific Bottlenose (Tursiops aduncus) and humpback (Sousa chinensis) dolphins off the South Coast of Zanzibar. Marine Mammal Science, 22(3), 667-682.

Tanzania Ports Authority. (2015). Tanzania Ports Authority annual report and accounts for the year ended 30th June 2014. 58pp. Ministry of Transport. Dar es Salaam.

Temple, A. J., Tregenza, N., Amir, O. A., Jiddawi, N., \& Berggren, P. (2016). Spatial and temporal variations in the occurrence and foraging activity of coastal dolphins in Menai Bay, Zanzibar, Tanzania. PLoS ONE, 11(3), e0148995. doi:10.1371/journal.pone.0148995

Thomas, L., Buckland, S. T., Rexstad, E. A., Laake, J. L., Strindberg, S., Hedley, S. L., . . Burnham, K. P. (2010). Distance software: design and analysis of distance sampling surveys for estimating population size. Journal of Applied Ecology, 47, 5-14. DOI: 10.1111/j.13652664.2009.01737.x.

Wells, S. (2009). Dynamite fishing in northern Tanzania - pervasive, problematic and yet preventable. Marine Pollution Bulletin, 58(1), 20-23. doi:10.1016/j.marpolbul.2008.09.019

Zanzibar Ministry of Livestock and Fisheries. (2010). Marine Fisheries Frame Survey for Zanzibar 2010.

931 
932 Table 1 - Summary of methods used to generate information on cetacean community

933 structure and threats in Tanzania

\begin{tabular}{|c|c|c|}
\hline Objective & Methods or Approach & Metric \\
\hline $\begin{array}{l}\text { Describe } \\
\text { Cetacean } \\
\text { Communities }\end{array}$ & 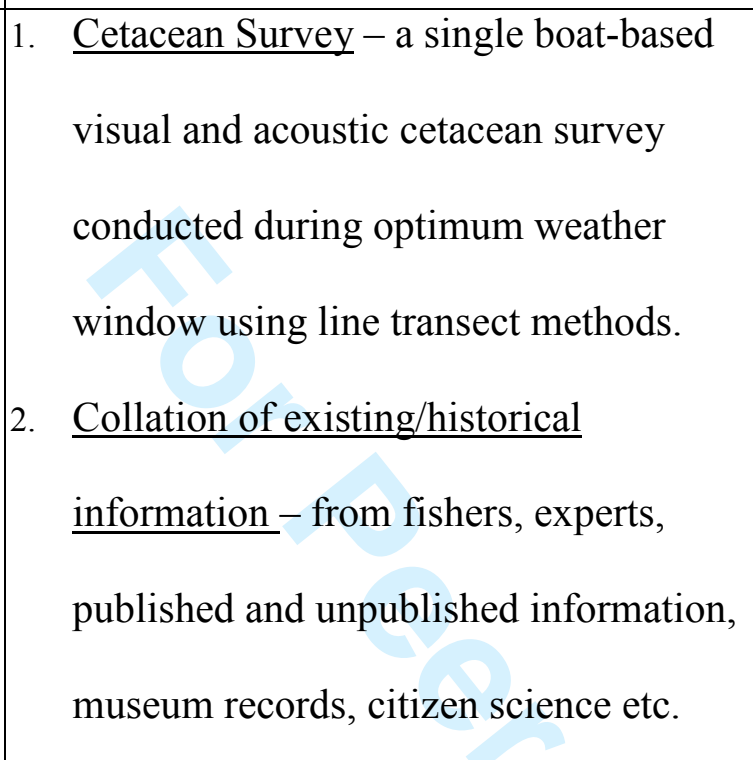 & $\begin{array}{l}\text { Index of diversity } \\
\text { Presence of threatened } \\
\text { species }\end{array}$ \\
\hline $\begin{array}{l}\text { Evaluate } \\
\text { potential } \\
\text { threats }\end{array}$ & \multicolumn{2}{|c|}{$\begin{array}{l}\text { General Approach } \\
\text { 1. Identify potential threats based on existing knowledge } \\
\text { 2. Gather semi-quantitative information to illustrate potential for key } \\
\text { threats to impact cetaceans throughout the study area (for specific } \\
\text { details, see below) } \\
\text { 3. Evaluate each risk spatially, rank and assign a score between } 0 \text { and } 100 \\
\text { according to relative risk (see Table } 4 \text { ). } \\
\text { 4. Assess the spatial overlap between cetaceans and potential threats to } \\
\text { identify priority areas for conservation (see Figure 5). }\end{array}$} \\
\hline & Evaluation of potential threats by zone & \\
\hline
\end{tabular}


2

3

4

5

6

7

8

10

11

12

13

14

15

16

17

18

19

20

21

22

23

24

25

26

27

28

29

30

31

32

33

34

35

36

37

38

39

40

41

42

43

44

45

46

47

48

49

50

51

52

53

54

55

56

57

58

59

60
1. Determine cetacean bycatch rates using Number of dolphins killed / fisher questionnaire surveys

year / per gillnet boat

2. Document total number of gillnetters

Total number of gillnets recorded in national fisheries surveys

3. Evaluate relative levels of port and ship related noise, disturbance, pollution, and potential for ship strikes from port authority records

4. Investigate presence of dolphin hunting, consumption and use of cetaceans through fisher interviews

Number of tons of goods brought to each port by ship / year

Proportion of fishers interviewed that claim that dolphins are hunted, eaten or sold in the market.

5. Analyse acoustic survey to quantify Mean number of blasts / $\mathrm{hr}$ incidence of blast fishing

934

935 
936 Table 2 - Species and number of groups of marine mammals detected visually and

937 acoustically during a March-April 2015 survey of the Tanzania coast

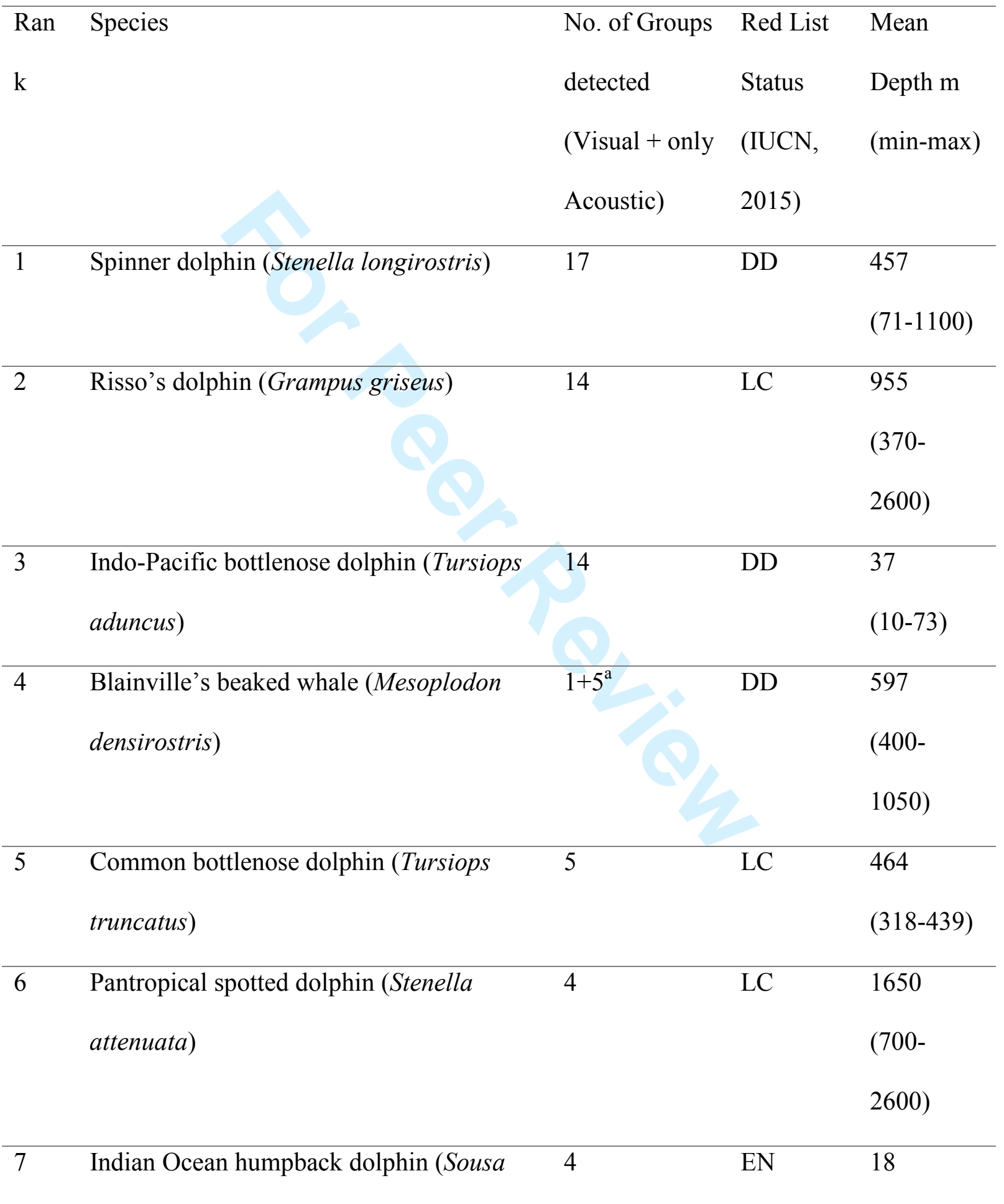




\begin{tabular}{llllc}
\hline 8 & Short-finned pilot whale (Globicephala & 2 & DD & \\
& macrorhynchus) & & \\
\hline 9 & Fraser's dolphin (Lagenodelphis hosei) & 1 & LC & 700 \\
\hline 10 & False killer whale (Pseudorca crassidens) & 1 & DD & 400 \\
\hline 11 & Dugong (Dugong dugon) & 1 & VU & 4 \\
& Unidentified & $11+11^{\mathrm{b}}$ & & - \\
& & $\mathbf{9 1}$ &
\end{tabular}

$938{ }^{a}$ One acoustic beaked whale detection included here may have been Blainville's or

939 Cuvier's beaked whale

$940{ }^{b}$ Eight of the acoustic detections included here as unidentified were assigned to spinner

941 dolphins by the whistle classifier which has a 70\% likelihood of being the correct

942 identification. 
943 Table 3 - Summary of marine mammals recorded during visual and acoustic survey of the coast of Tanzania

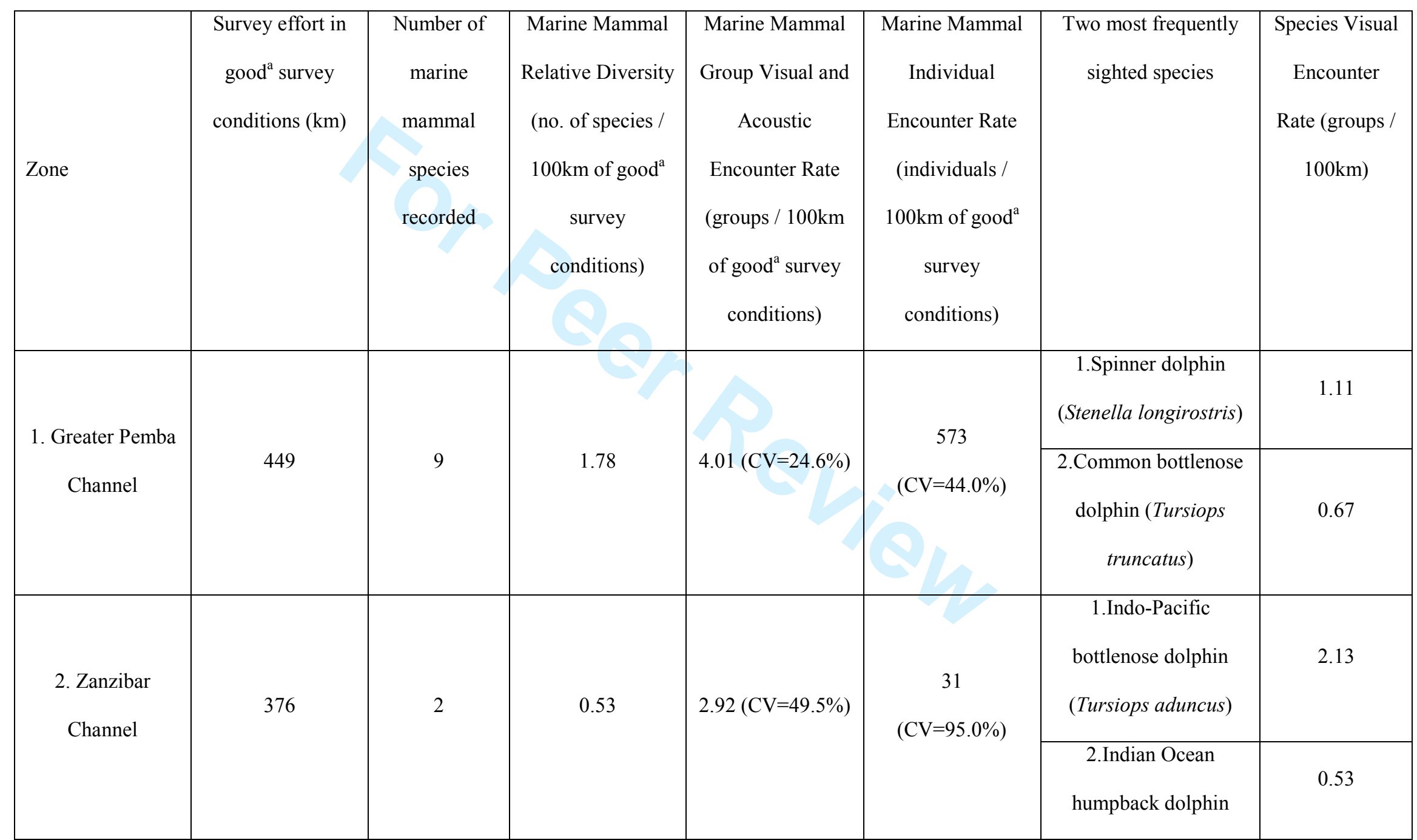

\section{4}

http://mc.manuscriptcentral.com/aqc 


\begin{tabular}{|c|c|c|c|c|c|c|c|}
\hline & & & & & & (Sousa plumbea) & \\
\hline 3. Dar es Salaam & 322 & 4 & 1.24 & $\begin{array}{c}3.11 \\
(\mathrm{CV}=23.3 \%)\end{array}$ & $\begin{array}{c}169 \\
(\mathrm{CV}=48.4 \%)\end{array}$ & $\begin{array}{c}\text { No species most } \\
\text { frequent }\end{array}$ & - \\
\hline \multirow[t]{2}{*}{$\begin{array}{l}\text { 4.Mafia, Kilwa } \\
\text { Rufiji }\end{array}$} & \multirow[t]{2}{*}{660} & \multirow[t]{2}{*}{6} & \multirow[t]{2}{*}{0.91} & \multirow[t]{2}{*}{$\begin{array}{c}2.12 \\
(\mathrm{CV}=43.6 \%)\end{array}$} & \multirow[t]{2}{*}{$\begin{array}{c}148 \\
(\mathrm{CV}=57.4 \%)\end{array}$} & $\begin{array}{l}\text { 1.Indo-pacific } \\
\text { bottlenose dolphin } \\
\text { (Tursiops aduncus) }\end{array}$ & 0.76 \\
\hline & & & & & & $\begin{array}{c}\text { 2.Spinner dolphin } \\
\text { (Stenella longirostris) }\end{array}$ & 0.30 \\
\hline $\begin{array}{l}\text { 5. Mtwara \& } \\
\text { Lindi }\end{array}$ & 560 & 4 & 0.71 & $\begin{array}{c}4.28 \\
(\mathrm{CV}=36.5 \%)\end{array}$ & $\begin{array}{c}340 \\
(\mathrm{CV}=41.2 \%)\end{array}$ & $\begin{array}{l}\text { 1.Risso's dolphin } \\
\text { (Grampus griseus) }\end{array}$ & 1.61 \\
\hline
\end{tabular}


946 Table 4 - Hierarchical scores and value of rapidly assessed potential threats to cetaceans in 947 Tanzania

\begin{tabular}{|c|c|c|c|c|c|}
\hline Potential Threat & Zone 1 & Zone 2 & Zone 3 & Zone 4 & Zone 5 \\
\hline $\begin{array}{l}\text { Bycatch Score } \\
\text { (dolphins/boat/year) }\end{array}$ & $\begin{array}{l}100 \\
(0.24)\end{array}$ & $\begin{array}{l}83 \\
(0.20)\end{array}$ & $\begin{array}{l}21 \\
(0.05)\end{array}$ & $\begin{array}{l}17 \\
(0.04)\end{array}$ & $\begin{array}{l}42 \\
(0.10)\end{array}$ \\
\hline $\begin{array}{l}\text { Gillnet Fishing Fleet } \\
\text { Score } \\
\text { (Gillnets/km of } \\
\text { coast) } \\
\text { (Total gillnets) }^{\mathrm{a}}\end{array}$ & $\begin{array}{l}57 \\
(40.3) \\
(4029)\end{array}$ & $\begin{array}{l}28 \\
(19.4) \\
(3022)\end{array}$ & $\begin{array}{l}7 \\
(4.9) \\
(315)\end{array}$ & $\begin{array}{l}100 \\
(70.4) \\
(15903)\end{array}$ & $\begin{array}{l}11 \\
(7.8) \\
(1529)\end{array}$ \\
\hline $\begin{array}{l}\text { Shipping Score } \\
\text { (M Tons of goods / } \\
\text { year) }\end{array}$ & $\begin{array}{l}3 \\
(0.37)\end{array}$ & $\begin{array}{l}1 \\
(0.15)\end{array}$ & $\begin{array}{l}100 \\
(14.3)\end{array}$ & $\begin{array}{l}0 \\
(0.05)\end{array}$ & $\begin{array}{l}2 \\
(0.35)\end{array}$ \\
\hline $\begin{array}{l}\text { Dynamite Fishing } \\
\text { Score } \\
\text { (blasts/hr) }\end{array}$ & $\begin{array}{l}14 \\
(0.76)\end{array}$ & $\begin{array}{l}27 \\
(1.41)\end{array}$ & $\begin{array}{l}100 \\
(5.31)\end{array}$ & $\begin{array}{l}11 \\
(0.59)\end{array}$ & $\begin{array}{l}13 \\
(0.68)\end{array}$ \\
\hline Total & 174 & 138 & 228 & 128 & 68 \\
\hline
\end{tabular}

$948 \mathrm{a}$ - numbers derived from the most recent Tanzanian mainland (Ministry of Livestock Development 949 and Fisheries, 2010) and Zanzibar (Zanzibar Ministry of Livestock and Fisheries, 2010), frame 950 surveys.

951

952 


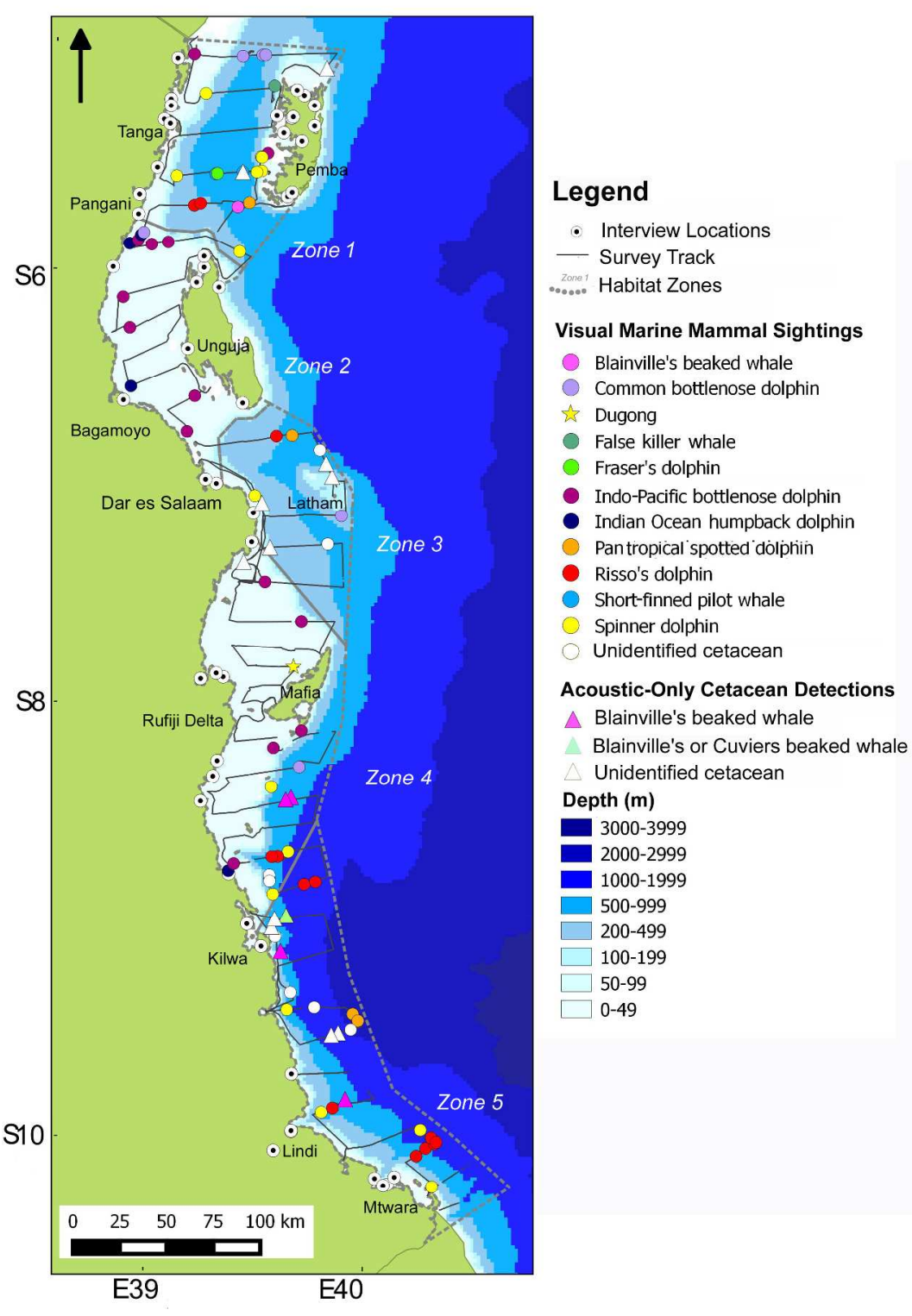

Boat survey track and the location of visual and acoustic marine mammal group detections made during the vessel-based cetacean survey of the entire coast of Tanzania conducted between March 4th and April 6th 2015.

$210 \times 311 \mathrm{~mm}(300 \times 300 \mathrm{DPI})$ 

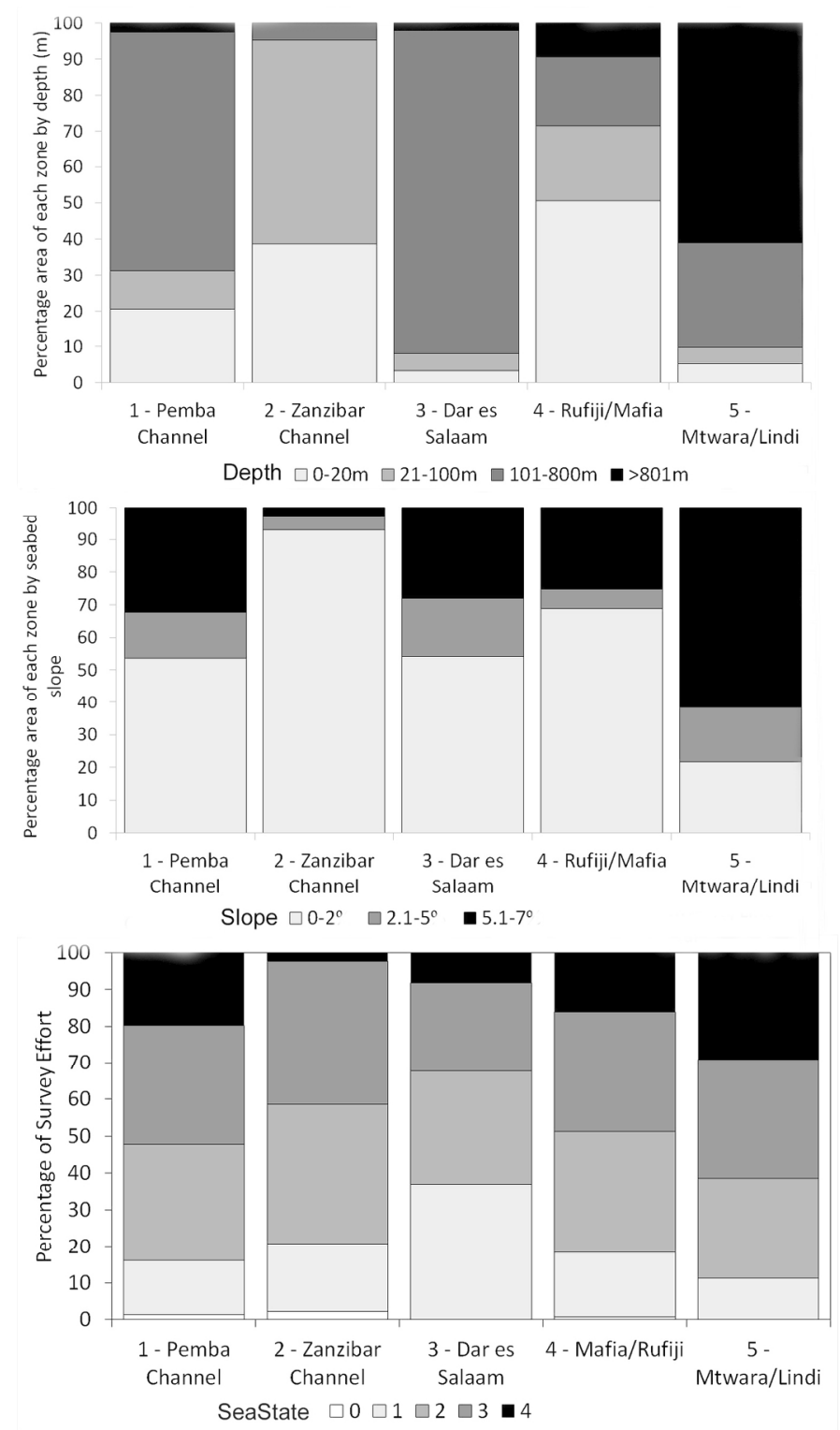

Summary of depth and slope habitat, and survey effort by sea state in each zone $115 \times 205 \mathrm{~mm}(300 \times 300$ DPI $)$ 
Marine mammal group and species encounter rates along the coast of Tanzania $58 \times 33 \mathrm{~mm}(300 \times 300 \mathrm{DPI})$ 

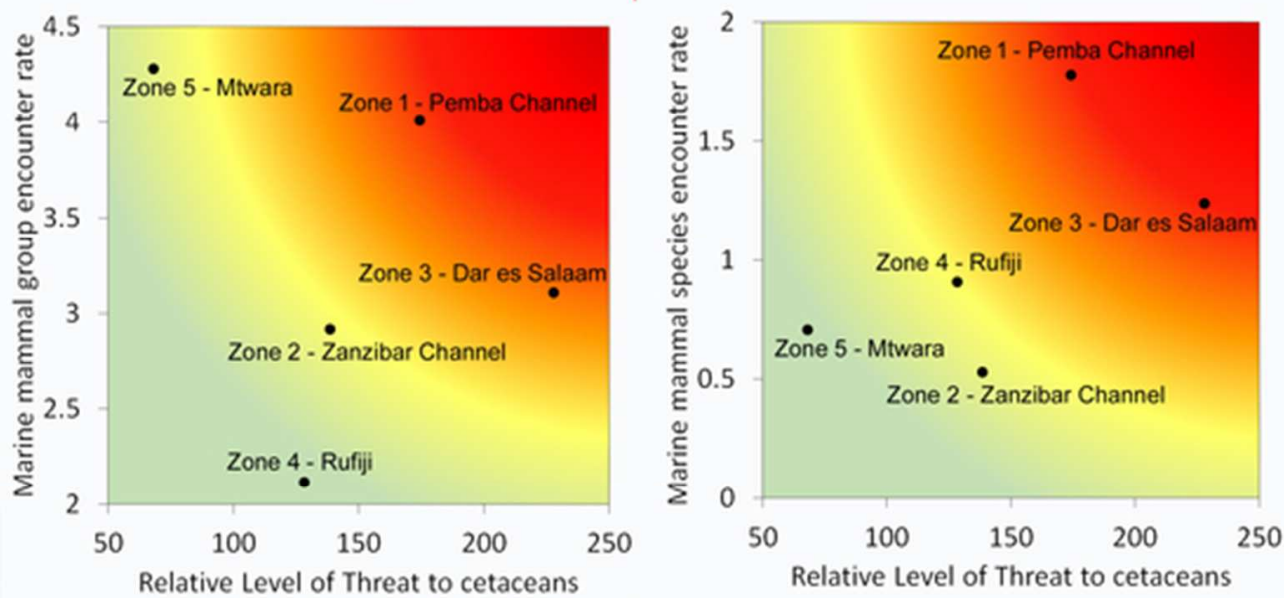

Relative cetacean encounter rate and relative cetacean diversity plotted against relative level of threat to cetaceans due to human activities in different zones in Tanzania.

$$
46 \times 22 \mathrm{~mm}(300 \times 300 \mathrm{DPI})
$$

